\title{
Kant and the forms of realism
}

\author{
Dietmar Heidemann ${ }^{1}[\mathbb{C}$
}

Received: 16 May 2018 / Accepted: 3 December 2019 / Published online: 7 December 2019

(C) The Author(s) 2019, corrected publication 2020

\begin{abstract}
Realism takes many forms. The aim of this paper is to show that the "Critique of pure Reason" is the founding document of realism and that to the present-day Kant's discussion of realism has shaped the theoretical landscape of the debates over realism. Kant not only invents the now common philosophical term 'realism'. He also lays out the theoretical topography of the forms of realism that still frames our understanding of philosophical questions concerning reality. The paper explores this by analysis of Kant's methodological procedure to distinguish between empirical (i.e. nonmetaphysical) and transcendental (metaphysical) realism. This methodological procedure is still of great help in contemporary philosophy, although it has its limits.
\end{abstract}

Keywords Kant · Realism · Idealism · Metaphysics · Transcendental philosophy · External world

\section{Introduction}

The aim of this paper is to show that the Critique of pure Reason is the founding document of realism and that to the present-day Kant's discussion of realism has shaped the theoretical landscape of the debates over realism. Kant not only invents the now common philosophical term 'realism'. He also lays out the theoretical topography of the forms of realism that still frames our understanding of philosophical questions concerning external reality. With few exceptions, like the Putnam of internal realism, the ongoing controversy over realism has ignored its own roots or is at least not aware that Kant has paved the way of our understanding of what

Dietmar Heidemann

dietmar.heidemann@uni.lu

http://www.philosophie.uni.lu

1 Institute of Philosophy, University of Luxembourg, 11, Porte des Sciences, 4366 Esch-Belval,

Luxembourg 
'realism' stands for, what principal forms of realism must be distinguished and how they are different. The reason for this might be that Kant grounds his own empirical realism on transcendental idealism, and that idealism does not seem to be attractive for the majority of contemporary philosophers.

On the standard view, idealism and realism are incompatible philosophical theories. For Kant, however, they are not. He rather claims that transcendental idealism and empirical realism form a unity, i.e., only in combination they demonstrate that objects of external perception are real: Transcendental idealists hold that the objects as we represent them in space and time are appearances and not things-in-themselves. This, according to Kant, implies empirical realism, i.e., the view that the represented objects of our spatio-temporal system of experience are real beings outside us. Whereas transcendental idealism lays out the way we represent objects, i.e., the transcendental conditions of our cognition of them, empirical realism expounds that objects, although cognizable only under these conditions, exist independently of us in space and time. Therefore, Kant argues, the combination of transcendental idealism and empirical realism avoids sceptical consequences with respect to the existence of the external world.

Clearly, transcendental idealism and empirical realism are not at the forefront of today's debates over realism. For many years even Kant scholarship has ignored the fact that Kant is not only a self-declared idealist but also a self-declared realist. ${ }^{1}$ In a way, this is surprising, all the more since Kant, in the Fourth Paralogism of the Critique of pure Reason (CPR A 366-380), introduces the concept "realism" (CPR A 369) to philosophy and offers an astute account of paradigmatic forms of realism, i.e., empirical and transcendental realism. ${ }^{2}$ As we will see, the disagreement between empirical and transcendental realism must be conceived in terms of the principal opposition between non-metaphysical and metaphysical forms of realism as they still occur in contemporary philosophy. My argument for why Kant's discussion of realism has systematic philosophical relevance for the debates over realism until today comes in two main steps. In Sect. 2 I show in some detail how Kant has shaped the theoretical landscape of the debates over realism in that he develops empirical realism by confronting the ontological and epistemic commitments transcendental idealists make with those of transcendental realists. Kant's distinction between empirical and transcendental realism turns out to be a classification

\footnotetext{
1 It is only within the last fifteen years or so that there has been a growing explicit interest in the kind of realism Kant holds himself. The most recent examples are Gurofsky (2018), Allais (2015), Westphal (2004) and Abela (2002). Examples of the older literature that address empirical realism in a broad sense are Okruhlik (1986), Stevenson (1983), Walker (1983), Walsh (1903, 1904).

${ }^{2}$ References made to the Critique of Pure Reason $(C P R$, first edition=A, second edition $=\mathrm{B})$ come from Kant (2000). The standard resources document that the notion 'realism' ('Realismus') has not been in use before Kant. Cf. Zedlers Universal-Lexicon (1731-1754) (https://www.zedler-lexikon.de/index .html?c=startseite\&l=de), Adelung: Grammatisch-kritisches Wörterbuch (1811) (https://lexika.digit ale-sammlungen.de/adelung/online/angebot), Grimm: Deutsches Wörterbuch (1854-1961) (https://www. zedler-lexikon.de/index.html?c $=$ startseite $\& l=\mathrm{de})$. The mediaevel universals controvery is not concerned with the modern (Kantian) problem of realism and is-like Descartes and other early moderns-only familiar with the notion realistae or realitas and its latin cognates. Cf. also the entry "Realismus" in Historisches Wörterbuch (1992).
} 
between the two principal forms of realism that have been debated ever since, i.e., non-metaphysical and metaphysical realism. As a matter of principle, any classification requires criteria by means of which it is possible to categorize something as something. In Sect. 3 I identify three criteria Kant applies in order to classify empirical and transcendental realism. These criteria serve-even today-as methodological tools for systematising the forms of realism. I show how these classificatory standards, i.e., the ontological, epistemic and veridical criterion, can be used and modified independently of historical context in order to generate a comprehensive variety of possible forms of realism as I conclude in Sect. 4. Hence, the aim of this paper is modest: On the backdrop of the historical finding that Kant introduces 'realism' and makes this concept available for general philosophical usage, I argue that he distinguishes principal forms of realism and that ipso facto Kant's pertinent distinction to a greater or lesser extent has shaped the theoretical landscape of philosophical realism to the present-day.

\section{Shaping the landscape: empirical and transcendental realism}

In his discussion of realism, Kant distinguishes between two basic forms of realism, i.e., empirical and transcendental realism. This distinction anticipates the nowadays common division between varieties of non-metaphysical and metaphysical realism. For Kant 'realism' is in fact a problem of classical metaphysics, more precisely of metaphysica specialis. Kant denies the possibility of rational, metaphysical cognition of the soul since we cannot have cognition independently of the conditions of the possibility of experience. This line of criticism implies that our ontological commitments cannot go beyond what we are able to cognize. The "Fourth Paralogism of Pure Reason" of the first edition of the Critique of pure Reason (A 366-380) makes this particularly clear. Here Kant confronts us with a Cartesian scenario, in which the exposition of the forms of realism is embedded. Accordingly, the fourth paralogism of the rationalist metaphysics of the soul turns out as a fallacy for the rationalist setting has sceptical consequences in that the existence of objects of outer perception is causally inferred from inner perception and doubtful as a result. It is doubtful because the external "cause of given perceptions" might in principle be produced by perception itself, for example by the power of imagination or inner sense, and as a consequence can never be known with certainty (CPR A 366). Only the object of immediate inner self-perception is undeniable, the Cartesian argues: "I myself with all my representations" (CPR A 368).

This sceptical argument is based on false metaphysical premises, Kant claims: First and foremost, the Cartesian doubt about the existence of the external world is unjustified because not only inner but also outer perception is immediate, and the objects of outer sense do not exist "independently of us and our sensibility" (CPR A 369). ${ }^{3}$ In particular, Kant challenges the Cartesian scenario by identifying the kind

\footnotetext{
${ }^{3}$ What Kant means is just that existence cannot be attributed to external objects independently of the transcendental conditions of the possibility of experience.
} 
of realism that underlies it, i.e., transcendental realism, and argues that this kind of realism, which turns out to be the prototype of what nowadays counts as metaphysical realism, has skeptical consequences and is therefore indefensible. By contrast, the kind of realism he holds himself, i.e., empirical realism, which nowadays figures as a form of non-metaphysical realism, does not have skeptical consequences. The question then is: What precisely is the difference between empirical and transcendental realism? In what follows, I will, first, discuss Kant's exposition of empirical realism and provide the reasons for why we should conceive of this theory as a nonmetaphysical 'one world' rather than a 'two worlds'-view (2.1). I shall then turn to Kant's exposition of transcendental realism and show why this theory amounts to a metaphysical 'two worlds'-view (2.2). From the binary picture of empirical and transcendental realism we can then move forward to the identification of the criteria by means of which Kant classifies the forms of realism in general.

\subsection{Empirical realism}

The starting point in Kant's discussion of realism is the problem of epistemic immediacy, i.e., the question of whether we are directly related to objects of outer perception, or whether outer perception is mediated through ideas, mental images or representations external objects cause in us. Kant holds epistemic immediacy. He establishes perceptual immediacy in the course of the paradigmatic distinction between what he coins empirical dualism, consisting of transcendental idealism and empirical realism on the one hand, and transcendental dualism, consisting of transcendental realism and empirical idealism on the other (CPR A 369-377). The opposition between both kinds of dualism is established in the following way: According to transcendental idealism, the objects of outer perception are appearances and not things-in-themselves. Just as little are space and time things-in-themselves or their properties but forms of our sensible intuition. As forms they ground the immediacy of perception, i.e., "that outer experience is really immediate" (CPR B 276), rather than causally mediated through representations of things-in-themselves outside us. ${ }^{4}$ This is the core idea of empirical realism, the view that the objects of outer senses are real in as much as they are objects of a possible experience for us, i.e., cognizable objects according to the transcendental conditions of experience as specified in transcendental idealism. To put it differently: Empirical realism is realism about appearances, i.e., about empirical things in space and there are no things-in-themselves outside space and time that account for their existence. It follows that since they are "separated from our sensibility", things-in-themselves, in empirical realism, correspond to no reality because they are conceived as "objects that are external in themselves" rather than external in space as the form of outer intuition (CPR A 370).

Not least because of his view that appearances are in space and "that space itself is in us" (CPR A 370) it has been argued that Kant forces himself into holding

\footnotetext{
${ }^{4}$ Empirical realists might thus be called 'direct realists': "Every outer perception therefore immediately proves something real in space, or rather is itself the real; to that extent, empirical realism is beyond doubt, i.e., to our outer intuitions there corresponds something real in space." (CPR A 375).
} 
unacceptable representationalist views about external reality since for the idealist empirical objects are appearances and appearances are representations such that in his theory external reality seems ungrounded (CPR A 369; A 490-493/B 518-521). A strict representationalist reading of Kant's doctrine might suggest this view, however, a more charitable and equally defensible reading does not. For Kant does not conceive of "Vorstellung" as re-presentation in the literal sense of a mental image like, e.g., Locke's idea that as the sole object of the mind mediates between the external world and our knowledge of it. Kant is not denying that the mind is capable of having mental images like in dreams, hallucinations or simply as products of the imagination. The notion "appearance", however, should not be understood as re-presentation in terms of mere mental image that closes the mind up from the world, or even as "mere illusion" ( $C P R$ B 69). Appearances are rather presentations a cognizer directly refers to in perception. ${ }^{5}$ For Kant perception is world-directed and not, e.g., sense datum-directed. Cognizers perceive appearances as objects in space rather than appearances as the causal mental products of objects in space. To be sure, Kant's use of "appearance" is ambiguous. On the one hand, "appearance" can mean just that, i.e., the mental presentation of an empirical object to which it directly refers (cf. e.g. CPR A 27/B 43); on the other, the term "appearance" can also refer to the perceived empirical object itself as its standard definition "undetermined object of an empirical intuition" (CPR A 20/B 34; cf. A 319/B 376 and A 480/B 508) indicates. Therefore, the usage of "appearance" and "representation" does not mean that Kant mentalises external reality in terms of phenomenalism. For on the phenomenalist reading truths about things-in-themselves are equivalent to truths about appearances. ${ }^{6}$ This, however, is not Kant's view since appearances are in space whereas things-in-themselves are not (see below).

For these reasons, Kant's, as it were, presentationalist terminology is not mentalist language and does not transform empirical realism into (Berkeleyan) metaphysical idealism, which dissolves external reality into a mere represented or perceived being. In Kant's theory "the objects of outer intuition are real too, just as they are intuited in space", i.e., as "extended beings in space". External objects are "real" in as much as "[...] they stand in an empirical connection with my real consciousness, although they are not therefore real in themselves, i.e., outside this progress of experience." (CPR A 491-493/B 520-521). Kant's realist commitment to the existence of objects in space independent of us but under the transcendental conditions of experience reveals that empirical realism is grounded on transcendental idealism. As a consequence, the meaning of predicates such as real, actual and even true cannot be established independently of transcendental idealism either. Statements like 'The chair I am perceiving is an actual object outside me.' or 'The objects in my visual field are real objects.' have objective meaning, that is, for Kant, they can be true judgments, only if they comply with the transcendental conditions of the possibility

\footnotetext{
5 On "Vorstellung" as presentation see also Gurofsky (2018), pp. 35, 70-104. Gurofsky argues convincingly that Kant does not belong to the way of ideas-tradition. See also Allais (2015), p. 25 and Van Cleve (1999), p. 123.

6 Cf. Van Cleve's (1999, here 71) phenomenalist reading of transcendental idealism.
} 
of experience. These conditions apply to the concept of 'truth' itself. For it doesn't seem to be consistent to constrain the objective validity of real and actual through transcendental conditions while allowing for metaphysical truth independently of such conditions. This would allow for the existence of cognition-transcendent facts the empirical realist denies. Consequently, the empirical realist must specify what it means for external world beliefs to be true, or as Kant says, what "the empirical truth of appearances" (CPR A 491-493/B 520-521) consists in.

On the face of it, the empirical realist conceives of truth in terms of coherence but this is not so clear. For famously Kant takes as "granted" the classical "nominal definition of truth" as correspondence which consists in the "agreement of cognition with its object" (CPR A 58/B 82). Still "granted" does not mean that Kant takes the correspondence theory of truth to be unproblematic. He rather considers it a matter of course, one to which theories must conform anyway. For evidently, agreement with the world is a necessary condition for true judgments about the world. Kant is, however, more reluctant to accept correspondence because a general criterion of truth is not available since there could not be anything general "which was valid of all cognitions without any distinction among their objects" (CPR A 58-59/B 83). What seems indisputable is that Kant has reservations towards truth as correspondence not least because he thinks, as we will see in Sect. 2.2, it is (metaphysical) correspondence that makes transcendental realism indefensible. For empirical realists "truth" is "empirical truth" and merely concerns external world beliefs, i.e., beliefs about appearances as ontologically independent, extended objects in space and time. It is in this sense that

"[...] the empirical truth of appearances is satisfactorily secured, and sufficiently distinguished from its kinship with dreams, if both are correctly and thoroughly connected up according to empirical laws in one experience [...] for everything is actual that stands in one context with a perception in accordance with the laws of the empirical progression." (CPR A 491-493/B 520$521)^{7}$

Evidently, behind this remark stands the "Second Postulate of Empirical Thinking": "That which is connected with the material conditions of experience (of sensation) is actual." (CPR A 218/B 266; A 225-226/B 272-275). ${ }^{8}$ The transcendental

\footnotetext{
7 The concept "empirical truth" should not be conflated with Kant's rather peculiar expression "transcendental truth" which designates the objective validity of the categories and "proceeds all empirical truth" (CPR A 146/B 185).

${ }^{8}$ In his critical philosophy Kant distinguishes between "actuality" and "reality". Whereas ("Wirklichkeit") or "existence" ("Dasein") is a modal category, "reality" ("Realität" from res 'Sache' or 'Sachhaltigkeit') is a category of quality. The category of "actuality", Kant claims, is derived from the assertoric form of judgment and determines, as "Second Postulate", that something exists or is there ("Dasein"). By contrast, "reality" is derived from the affirmative form of judgment in so far as something is thought to have a (sensible and/or nonsensible) quality. Thus, everything that is actual is also a reality but not everything that is thought as a reality is actual. It should be noted, though, that the English translation of the German 'äußere Wirklichkeit' as 'external actuality' sounds rather unfamiliar. In many cases 'external reality' or 'outside world' therefore means 'external' or 'outside actuality' (äußere Wirklichkeit) in Kant.
} 
principle of actuality implies that we are objectively justified in applying the concept of actuality or existence only to possible objects of our spatiotemporal system of experience. That is this concept is objectively valid only if it coheres with the cognitive restriction of transcendental idealism such that we cannot analytically determine the truth of existential claims about external reality, i.e., based on the "mere concept of a thing", because "perception" is the "sole character of actuality" (CPR A 225/B 272f.). Here the concept of empirical truth, in the sense of empirical reality, and henceforth Kant's coherentist understanding of "truth" emerges. Accordingly, only that is actual and a possible object of true world directed judgments, what coheres with the a priori concepts and forms that govern experience and, as Kant specifies in the transcendental Dialectic, "stands in one context with a perception in accordance with the laws of the empirical progression" ( $C P R$ A 493/B 521). We can therefore objectively refer the concept actual or true respectively to, e.g., absent (unperceived) objects or facts as long as these objects or facts are perceived "in the continuation of experience" (CPR A 493/B 521). Can correspondence be integrated in this view since Kant insists that true world directed judgments or cognition must be in agreement with the world? If we take nominal 'correspondence' to reflect the 'nature' of truth-"Truth [...] rests upon agreement with the object" (CPR A 820/B 848)-in that it expresses whether or not something is the case in the world this is not a problem: But for empirical realists this correspondence-relation can only be established if it coheres with the transcendental principles of the understanding and does not make any assertion about a purportedly cognition-transcendent reality or truth independently of these principles. ${ }^{9}$

Ever since the publication of the first Critique critics have raised the objection that as a consequence of this kind of transcendental cognitive restriction, empirical realists are compelled to make existence claims about unknowable things-inthemselves. For without things-in-themselves the empirical realist would not be in a position to conclusively explain the existence of appearances. The empirical realist then seems to be a realist with respect to appearances and things-in-themselves at the same time. This, however, is inconsistent since how can she know that thingsin-themselves exist if they are unknowable. In order to show why empirical realism is not realism with respect to things-in-themselves, I will briefly turn to the debate between the proponents of the 'one world'- and 'two worlds'-interpretation of transcendental idealism. The debate reveals that empirical realism coincides with what nowadays counts as forms of non-metaphysical realism.

On the 'two worlds'-interpretation' of transcendental idealism, things-in-themselves are required in order to ground appearances. But appearance and thing-initself are numerically distinct objects that do not just belong to different regions or layers of one world but occupy two different worlds, usually conceived as the sensible and the intelligible world. Nowadays many Kant scholars find this view rather

\footnotetext{
${ }^{9}$ For an in-depth study of Kant's theory of truth see the clarifications in Sabrina Bauer's recent dissertation Der Wahrheitsbegriff in Kants Transzendentalphilosophie. Eine Untersuchung zur Kritik der reinen Vernunft, Diss. University of Heidelberg, 2019. Bauer makes the case that Kant opts for correspondence rather than coherence.
} 
unconvincing since it makes unprovable metaphysical claims about causally affecting noumena in the intelligible world that somehow yield appearances in the sensible world. In particular, it merely speculates about how the causal transfer between the two worlds materializes and whether it can at all. Kant says it himself: "The division of objects into phaenomena and noumena, and of the world into a world of sense and a world of understanding, can [... ] not be permitted at all" (CPR B 311). ${ }^{10}$

The 'one world'-interpretation seems to avoid these problems. For on the 'one world'-reading the concepts "appearance" and "thing-in-itself" refer to the same object such that the metaphysical allegation about a second world is dispensable. The challenge for the 'one world'-interpretation then is to provide a reasonable account of how to conceive of the same (empirical) object as appearance and thing-in-self all at once. Like the 'two worlds'-interpretation the 'one word'-interpretation takes many forms. The most debated one is the 'two aspects'-view and comes in two main versions, the epistemic (methodological) and the ontological (metaphysical) one. According to the epistemic 'two aspects'-view, as defended by Prauss (1974) and Allison (2004), the same empirical object can be considered as appearance and as thing-in-itself. Considering an object as thing-in-itself means to consider it independently of the transcendental conditions of cognition while not claiming its existence. What exists rather is the cognizable, empirically real object in space and time, i.e., appearance. For the purpose of this article I can leave it open whether the epistemic 'two aspects'-view as such is persuasive or not. At any rate this view does not make existence claims about unknowable second-world-objects, things-in-themselves, and therefore does not violate cognitive restriction. The proponents of the epistemic 'two aspects'-view are just empirical realists, i.e., realists about appearances. ${ }^{11}$

The ontological or metaphysical 'two aspects'-view dismisses not only the 'two worlds-' but also the epistemic 'two aspects'-interpretation. On this reading, objects have knowable phenomenal aspects and unknowable noumenal or in-itself-aspects. The former is what makes an object an appearance, the latter makes the same object a thing-in-itself. Since appearances exist, and since they can only exist if they are grounded through things-in-themselves, things-in-themselves must exist, too. Here again the difficulty is that because of cognitive restriction, we cannot know anything about things-in-themselves and can therefore only presume that they exist. The proponent of the metaphysical 'two aspects'-view is therefore a realist with respect to appearances and things-in-themselves. In Manifest Reality (2015) Lucy Allais presents a version of the metaphysical 'two aspects'-view that seems to offer a way out of the presumption-difficulty. On Allais' reading transcendental idealists make "substantial metaphysical commitments: to the mind-dependence of things as they appear to us, and to the existence of an aspect of reality that grounds the

\footnotetext{
10 Commentators like Van Cleve (2003, pp. 194-195) who nonetheless cling to "a two-worlds view" argue that transcendental idealism is phenomenalism "since appearances are only virtual objects". The problem, however, is that although phenomenalism pushes Van Cleve towards "a two-worlds view", he, inconsistently to my mind, simultaneously holds that appearances "do not form a second world".

${ }^{11}$ Critics of Allison (and Prauss) have worries about the ontological status of things-in-themselves within the 'two aspects'-view and its inherent anthropocentrism. Cf., e.g., Gurofsky (2018), pp. 46-56, and Allais (2015), pp. 79-89.
} 
appearances of things, and which we cannot cognize." 12 What is manifest then is the appearance-aspect, and what is non-manifest is the in-itself-aspect of the same object in the same one world. Now Allais' claim is that unlike the 'two-worlders' she is not illegitimately presupposing the existence of the thing-in-itself. She accepts that we cannot have access to things-in-themselves and that we cannot know that they exist through intuition either. Nonetheless they must exist because, according to Kant, "it is a conceptual truth that where there is something that appears in a certain way to us there is something that has a way it is in itself". ${ }^{13}$ Moving from the aspect or "way" a thing appears to the aspect or "way it is in itself", does not mean to introduce a second reality or object. For the "appearance"-"way" and the "in itself"-"way" are about the same reality or object. For this reason, Allais believes to do justice to Kant's supposedly existential claim about things-in-themselves while not violating cognitive restriction such that he would count as a realist about appearances and things-in-themselves. Allais' recently much debated and widely celebrated metaphysical two-aspects reading must be ruled out in order to show that we cannot understand empirical realism as a form of realism that, while denying cognitive access to things-in-themselves, allows for at least some kind knowledge of their existence. For if the metaphysical two-aspects reading would hold, empirical realism could not count as non-metaphysical realism, i.e., a form of realism that does not allow for the reality of a cognition-transcendent domain of objects.

There are four major difficulties with the metaphysical two-aspects interpretation: The first difficulty is that if things-in-themselves are the grounds of appearances then, since they are cognition-transcendent, we cannot know anything about their grounding. In particular, we cannot be sure whether the appearance-aspect really is what the in-itself-aspect grounds. For even if cognition-transcendent things-inthemselves exist, it does not follow from their alleged existence as a conceptual truth about them that they ground appearances in any specific way. Therefore, Allais must leave it open why a thing appears in this rather than in another way, or whether the in-itself-aspect is not deceiving us by grounding 'false' appearances. For instance, how can I be sure that a red-appearance of an object is in fact caused by a red-initself-aspect attributed to a cognition-transcendent object? The metaphysical 'two aspects'-interpretation has rather sceptical consequences that are similar to those that Kant finds in transcendental realism (see below 2.2).

The second difficulty is that the proponent of the metaphysical 'two aspects'interpretation must know more about things-in-themselves than she pretends to. She not only knows that things-in-themselves exist but she must also have objective cognition about their (as Allais presumes: causal) grounding and by implication she must also objectively know that in-itself-aspects are properties that have powers to do something, e.g., connecting up with other properties and so on and so forth. This clearly is in conflict with the ignorance claim about in-itself-aspects.

\footnotetext{
12 Cf. Allais (2015), p. 7. According to Allais' 'two aspects'-approach, Kant is committed "to the existence of an aspect of reality that we cannot know" (pp. 11, 15, 221, see 59-76).

13 Cf. Allais (2015), p. 69. Here it remains unclear why, as Allais believes, "conceptual truth" is different from truth "on the basis of an analytic judgment" (70).
} 
The third difficulty concerns the question of what the appearance- and in-itselfaspects are aspects of. From the start Allais distinguishes "the way things appear in perceptual experience and the way they are apart from this", i.e., in themselves. ${ }^{14}$ By implication, the "things" the appearance- and in-itself-aspects belong to, are different from the aspects themselves. What are those "things" if only their manifest aspects can be known and if they are also different from the in-itself-aspects? If, as Allais suggests, the in-itself-aspects ground the manifest aspects, it is not the "things" that do the grounding. Are "things" then to be conceived as underlying substances? If so, are they unspecified material entities? How does the dualist picture of manifest qualities and in-itself-aspects fit together with the third dimension of, as Allais says, "things, understood neutrally"

The fourth difficulty is that if the metaphysical 'two aspects'-view would be true then things-in-themselves would need to be in space. For if they were not, we could neither attribute to them existence nor grounding since, on this view, there is only one world and if things-in-themselves exist and have causal powers such that they (causally) ground appearances, they must be somewhere, i.e., in space. But according to Kant things-in-themselves are not spatial: "space comprehends all things that may appear to us externally, but not all things in themselves". (CPR A 27/B 43) ${ }^{16}$ The claim that things-in-themselves are not in space has broad implications that I cannot fully discuss here. The following is, however, crucial for showing why Kant is not a realist with respect to things-in-themselves but only with respect to appearances, i.e., an empirical realist: For Kant true existential judgments about external objects imply that these objects exist in space. Now, everything that exists in space is cognizable, which means, for Kant, that we can in principle identify the properties actually or potentially pertaining to these objects. This is evidently in conflict with Allais' view that things-in-themselves are spatial but not cognizable. But maybe things-in-themselves are special in that they exist, although, not as empirical things in space. Kant is in fact considering this possibility which he attributes to Leibniz who conceives of things-in-themselves as merely intelligible things (intelligibilia). Kant accepts Leibniz' view 'that relational concepts absolutely presuppose given things and are not possible without these." (CPR A 284/B 340) For Leibniz there are then inner determinations that ground outer (spatial) relations of things. But this is only (conceptually) true of intelligible things or relations because we obviously cannot conceive of relations without there being something that is related (e.g. Leibnizian monads). This the inner grounding the outer-relation, i.e., non-spatial

\footnotetext{
14 Cf. Allais (2015), p. 117.

15 Cf. Allais (2015), p. 35. For a similar objection cf. Gurofsky (2019).

16 A reviewer for this journal points out that it is nonetheless consistent with Kant's theory that, e.g., thoughts and representations are not in space although cognizers are. Cf. also the secondary quality analogy that Kant mentions in the Prolegomena (AA IV:289; Kant 2004b, pp. 40-41). I am grateful to the reviewer for this important hint. On non-spatiality of things-in-themselves see also CPR A 563/B 591: "The world of sense contains nothing but appearances, $[\ldots]$ and $[\ldots]$ here we never have to do with things in themselves as our objects", and CPR A 490/B 518: "everything intuited in space or in time, hence all objects of an experience possible for us, are nothing but appearances". Cf. equally CPR A 26/B 42, A 276f/B 332f.
} 
things-in-themselves (noumena) grounding spatial relations, however, does not hold true with respect to the space we know, i.e., space as form of sensible intuition. For we represent space as an intuitional system of relations. As a represented given relational whole, i.e., intuiton, space precedes the spatial things and is therefore "a necessary condition of all the relations within which objects can be intuited as outside us" (CPR A 27/B 43). The relations among spatial objects we can possibly know are therefore fundamentally different from the relations that obtain among things-inthemselves or noumena. Consequently, unlike Allais claims, if there are things-inthemselves they cannot be in space but must be outside space. ${ }^{17}$

For this reason, the metaphysical 'two aspects'-view is flawed since the claim that things-in-themselves are in space is unsustainable. However, Allais seems to offer a way out here in order to save her interpretation. She contends that the notions "things-in-themselves" and "noumena" do not have the same referent and that Kant dismisses what she calls "noumenalism", the idea that things-in-themselves are nonspatio-temporal, non-sensible objects, i.e., intelligible things. ${ }^{18}$ This claim is hard to defend, though, since Kantian things-in-themselves are noumena. Kant unmistakably says that the "world of sense" does not contain "things-in-themselves" (CPR A 563/B 591). Thus, things-in-themselves are non-sensible objects, i.e., noumena or pure objects of thought. This is what Kant reiterates at numerous places: "The concept of a noumenon, i.e., of a thing that is not to be thought of as an object of the senses but rather as a thing in itself (solely through a pure understanding)" (CPR A 254/B 310); "our understanding" calls "things in themselves (not considered as appearances) noumena" (CPR A 256/B 312); the "transcendental use" of the "categories" is not admissible because otherwise they would not "hold of possible experience but rather of things in themselves (noumena)" (CPR A 258f/B 314f; cf. B 307). As a consequence, things-in-themselves are noumena and if they exist, they would not be spatial. This brings the metaphysical 'two aspects'-view close to what Kant terms "transcendental realism", i.e., the metaphysical form of realism about things-in-themselves that he opposes to non-metaphysical, empirical realism about appearances.

\subsection{Transcendental realism}

As we have seen in the previous section, empirical realism is realism about appearances, i.e., empirical things, and nothing beyond. By contrast, transcendental realism is realism about things-in-themselves. Transcendental realists "represent[] outer appearances [...] as things in themselves", i.e., "which would exist independently of us and our sensibility", inasmuch as space and time are understood as "given in themselves" rather than as conditions or forms of human sensible intuiton (CPR A

\footnotetext{
17 Cf. Allais (2015), pp. 231-258. Buroker (1981), chap. 3-5, provides an insightful reconstruction of Kant's argument. Although Allais (2015), p. 227 is familiar with this reconstruction she does not discuss it. Cf. Buroker (2006), pp. 64-68. See also Allison (1976).

18 Cf. Allais (2015), pp. 11, 15, 59-65.
} 
369). ${ }^{19}$ For transcendental realists objects of outer perception are-as we will see in Sect. 3-ontologically and epistemically independent of us because on their view the objective validity of the concept 'actuality' or 'existence' does not depend upon a conceptual framework within which only it can be legitimately applied. Accordingly, in transcendental realism there is no justificatory connection between what we can cognize, i.e., the mental representation of external reality, and what is real. As a consequence, transcendental realists consider outer perception as actual insofar as perception is caused by things-in-themselves in space outside us. Since this causal relation is not determined through a priori principles of experience, e.g., through transcendental conditions of the possibility of experience, outer perception cannot, in transcendental realism, ever be traced back with certainty to its external cause. For such a causal relation might be "a mere play of our inner sense" (CPR A 368). The empirical realist, too, does not deny that outer perceptions can be a product of the imagination or the inner sense. But unlike transcendental realists, empirical realists are not forced into sceptical conclusions, Kant claims, because transcendental idealists do not conceive of appearances as mental images or ideas. ${ }^{20}$

Transcendental realists and empirical idealist are natural allies. For empirical idealism is a sceptical view the transcendental realist cannot avoid. If external objects are things-in-themselves then our cognitive access to the world is indirect, i.e., mediated through representations in us caused by something outside us. In that sense, transcendental realism is indirect realism. Here 'representation' must be taken in the literal sense as re-presentation, i.e., an inner idea or mental image of the thing outside the cognizer. The empirical idealist is someone, Kant says, who "cannot really perceive external things, but only infer their existence from [...] inner perception." (CPR A 369) Empirical idealists do in fact concede outer experience cognizers have of things-in-themselves but they leave open whether "the object corresponding to it also exists" (CPR A 371), i.e., whether a representation of an object has a corresponding external cause. Transcendental realists can thus not prove the causal correspondence between representation and represented object because the supposition of space and time existing in themselves opens up a gulf between cognition in us and the cognized outside of us, a gulf that cannot be bridged by outer perception. This cognitive incapability constrains transcendental realists to consent to empirical idealism. The transcendental realist herself obviously contests any putative alliance with empirical idealism for she does not doubt the existence of things in space. The world is rather there as it is. Scepticism about external objects is, however, unavoidable for any form of realism, Kant argues, that like transcendental realism takes the world to exceed the possibility of cognition.

If external objects were in fact things-in-themselves, as transcendental realists hold, then reality (the world or what is actual) could in principle go beyond what

\footnotetext{
19 CPR A 491/B 519: "The realist, in the transcendental signification, makes mere representations into things in themselves." Cf. also CPR A 181/B 223f.; A 270f/B 326f.

${ }^{20}$ Given this threat of scepticism it is hard to see why Allais (2003), p. 379, alleges that "Kant is a transcendental realist with respect to things as they are in themselves." See similar Langton (1998). Westphal (2004), p. 223, believes that transcendental idealism is false and that Kant endorses transcendental realism as "unqualified" realism.
} 
we can possibly cognize. That is to say, the transcendental realist acknowledges that ipso facto there might be regions of reality, e.g., existing facts, that cognition will never be able to access, such that we can never know whether they are real and what the scope of 'reality' eventually is. In this sense 'reality' does not depend on what we can know in general. For transcendental realists reject transcendental conditions of the possibility of experience. By contrast, for empirical realists the objective truth of the concept of 'reality' is bound to the theoretical framework, i.e., transcendental idealism, that restricts its objective meaning to objects of human sensible intuition in space and time. Reality as such can thus not be experience- or cognition-transcendent. The transcendental realist denies this because on her view 'reality' does not depend on the cognitive make-up of the knowing subject. Parts of reality might eventually be experience- or recognition-transcendent. For this reason, the transcendental realist cannot even be sure that external objects exist for she can only suppose that outside representations have real external causes in space, i.e., that her external world beliefs in fact correspond to what is the case in the world. ${ }^{21}$ Accordingly, she cannot know whether the world is as she represents it for empirical, causal inferences from mental representations to their external causes are unreliable and objects of mere speculative: "the inference from a given effect to its determinate cause is always uncertain, since the effect can have arisen from more than one cause." (CPR A 368).

The metaphysics that Kant imposes on transcendental realism corresponds to the Cartesian sceptical scenario of the evil demon, i.e., the scenario of the sceptical hypothesis. Accordingly, we cannot know whether our beliefs are true. This is what Kant thinks transcendental realism necessarily results in. Even if the transcendental realist justifies her beliefs by employing the best methodological or scientific means available, she can never be sure whether or not she is mistaken about the source of her beliefs. For according to the sceptical hypothesis, the causes of our worldly representations can in principle be experience- and cognition-transcendent. Again, the reason for this is that in transcendental realism reality can go beyond what we are able to cognize. The connection between realism and scepticism has been widely discussed in contemporary philosophy. Kant was already fully aware that certain metaphysically motivated realist commitments result in sceptical consequences. To put it differently, as Stroud, Nagel and others have emphasized, metaphysical or transcendental realism seems to be a necessary presupposition the sceptic tacitly accepts in order to make sceptical doubts intelligible. For only if the world is metaphysically mind-independent, the sceptic can at all suppose that we cannot know whether our beliefs are true. ${ }^{22}$

What has been achieved so far? The aim of this section was to outline how Kant has shaped the theoretical landscape of the debates over realism by distinguishing two principle forms of realism, i.e., empirical and transcendental realism. This

\footnotetext{
${ }^{21}$ In terms of theory of truth Kant consequently conceives of the transcendental realist as holding correspondence. See Sect. 3 below.

22 Cf., e.g., Stroud (1984), p. 82: "the source of the philosophical problem of the external world lies somewhere within [...] a conception of an objective world“. See Nagel (1989), chap. 5 and 6.
} 
distinction foreshadows the now standard divide between non-metaphysical and metaphysical forms of realism. And as we have seen, empirical realism is not a hybrid form of realism that allows for non-metaphysical and metaphysical ingredients at once, as the metaphysical 'two-aspects-interpretation' suggests. Now that we have a clear picture of what Kant thinks 'realism' amounts to and what principle forms of realism must be distinguished, the question is whether his classification of types of realism operates on a systematic theoretical basis, or whether it rather is piecemeal. As I show in the following section, it is possible to identify three criteria by means of which Kant systematically classifies the forms of realism. Furthermore, these criteria can serve as general classificatory tools of distinguishing forms of realism even beyond Kant.

\section{Classifying realism: non-metaphysical and metaphysical}

Kant sets the theoretical cornerstones that structure the realism debate since it emerged under the heading 'realism' by the end of the eighteenth century. The springboard of the debate is Kant's distinction between empirical and transcendental realism. Empirical and transcendental realism prefigure the more recent conceptual dichotomy between non-metaphysical and metaphysical forms of realism. Metaphysical realists typically hold that the world exists independently of what we can know such that reality can go beyond what we can cognitively access. By contrast, non-metaphysical realists typically hold that the world depends on what we can know after all, in the sense that we cannot meaningfully claim something to exist while acknowledging that we cannot have cognitive access to it. Now the difficulty already seen by Kant is that in methodological terms we need a sufficiently clear set of criteria by means of which it is possible to make such a distinction. Kant realized that it is much too unspecific to just operate on the generic understanding of realism as the view that the world does really exist, not least because the realism he defends himself must be somehow distinguishable from the form of realism he discards, i.e., transcendental realism.

Evidently, for Kant realism takes many forms, and these forms need to be organized according to specific criteria in order to make them intelligible as well as distinguishable. The differentiation between empirical and transcendental realism in the previous section reveals that in his analysis of realism Kant implements three criteria. These criteria allow for systematising the main distinguishing features of each form of realism and thereby for pinpointing their main differences. In order to profile the forms of realism Kant applies, as I shall call them, (a) the ontological, (b) the epistemic, and (c) the veridical criterion:

(a) The ontological criterion defines whether a particular form of realism takes the world to exist dependently or independently of the mind, i.e., the mind's actual perception. This criterion is not trivial since some realists claim that the world's existence depends on its being perceived by God's or the human mind whereas others reject this claim as unintelligible. 
(b) The epistemic criterion specifies whether or not, according to a form of realism, existential and objective claims in general about the world depend on what we can know in general such that what we conceive as real can or cannot go beyond what we can know. The epistemic criterion is pivotal inasmuch as forms of metaphysical realism claim that the world inhabits experience- or cognitiontranscendent facts whereas non-metaphysical forms of realism deny this.

(c) The veridical criterion determines the truth conditions of our external world beliefs, i.e., whether our beliefs about the world are made true by the world or whether the truth of external world beliefs can only be established within the cognitive theory that underlies them. This criterion is indispensable because a form of realism cannot limit itself to consistency of the claims it makes about external things but as a theory it must be able to explain whether or not these claims are true.

\subsection{Applying Kant's classificatory criteria}

If we start from 'realism' as the generic view that the world exists and move on to specifying it by applying Kant's criteria, what we receive is the dichotomy between metaphysical and non-metaphysical realism: First, for metaphysical realists the world is ontologically independent of the mind, i.e., the world's existence does not depend on a cognizer's mental activity. Second, metaphysical realists hold epistemic independence such that the world can go beyond what we can know in general. Third, in veridical respect metaphysical realists advocate truth theoretical correspondence, i.e., the view that all meaningful statements about the world are made true or false by the world only. By contrast, non-metaphysical realists, first, accept that the world is ontologically independent of the mind but, second, hold epistemic dependence because on their view reality cannot go beyond what we can know, i.e., for every actual object it is the case that it can be cognitively accessed in principle. Third, in veridical respect non-metaphysical realists hold truth theoretical coherence, i.e., the view that all meaningful statements about the world are true or false only in accordance with the epistemic principles set up in a theory.

Applying these criteria to empirical and transcendental realism, as Kant explicitly does in the Fourth Paralogism, brings to light a picture that exactly parallels the characterisation of non-metaphysical and metaphysical realism:

\subsubsection{Metaphysical/transcendental realism}

First, transcendental realists hold ontological independence because for them external objects (the world) "exist independently of us and our sensibility" (CPR A 369). Second, transcendental realists argue for epistemic independence since for them predicates like 'actuality' or 'existence' do not depend on what we are able to cognize in general (CPR A 368, A 371-372). Third, transcendental realists are committed to veridical correspondence, that is to the "corresponding" between mind or existential propositions about the world and facts in the world such that every meaningful statement about the world is either true or false (CPR A 371, 375). 


\subsubsection{Non-metaphysical/empirical realism}

First, empirical realists subscribe to ontological independence because they hold that the world exists independently of the mind and that extended objects exist "in space" outside us, for physical reality "cannot be invented by any power of imagination or produced independently of perception" (CPR A 373). Second, empirical realists hold epistemic dependence because they maintain that reality is dependent upon that which we can cognize in general, i.e., what counts as actual must be essentially a possible object of human cognition (CPR A 369). Third, empirical realists hold veridical coherence because in empirical realism external world beliefs are true only in accordance with transcendental principles of cognition (CPR A 376). ${ }^{23}$

Although this juxtaposition of transcendental/metaphysical realism on the one hand, and empirical/non-metaphysical realism on the other, looks like a clear-cut division, its philosophical significance could be called into doubt. Critics might object that in this classification the distinction between transcendental and empirical realism is not sufficiently clear because both theories make the same basic ontological claim: the world exists independently of the mind. This cannot be denied, however, as we have seen in the previous section, in both forms of realism 'world' has fundamentally different referents: As I have argued, for empirical realists only appearances exist, whereas transcendental realists claim that things-in-themselves exist. On the face of it, this seems to be just a matter of terminology, but it is not because transcendental realists allow for the existence of objects that cannot be cognized whereas empirical realists don't. What both agree on is that the existence of what their realism is about, appearances or things-in-themselves, respectively, is not the product of a mind's activity. That is, things outside us are ontologically independent. But as the second and third criterion show, ontological mind-independence can be spelled out in fundamentally different ways.

Here another point of criticism might arise. Over the past five decades or so a substantial part of the realism debate has been devoted to (semantic) anti-realism, the view that meaningful statements about the world can be true only if cognizers are able to know its truth and have evidence for its truth. For (semantic) anti-realists like Dummett such statements cannot "possess an objective truth-value, independently of our means of knowing it", i.e., they cannot be "true or false in virtue of a reality existing independently of us." ${ }^{24}$ Not least because of Putnam's reappraisal of transcendental idealism in terms of internal realism it has been argued that the rejection of cognition- and verification-transcendence sounds rather Kantian, and that empirical realism therefore is a form of anti-realism. ${ }^{25}$ In the more recent literature, however, this interpretation has been disputed for the most part. Allais in

\footnotetext{
23 As I have indicated above, the difficulty is that Kant does not hold pure coherence since for him true beliefs about the world must also correspond to the world. As Bauer (2019) shows, correspondence is pivotal for Kant. This has implications for the question of whether empirical realism is nothing over and above ant-realism (see below).

${ }^{24}$ Cf. Dummett (1978), p. 146.

25 See Putnam (1980, 1981, 1982, 1983, 1987, 1988, 1990, 1999). Cf. Moran (2000), Stevenson (1983) and Walker (1983).
} 
particular argues that although (semantic) anti-realism can "help us to understand" Kant's doctrine, "there are profound differences between the Kantian position" and this view. On Allais' reading, both theories likewise reject experience-transcendence of appearances (empirical things), but they are different mainly because Kant, unlike (semantic) anti-realists, accepts verification-transcendent reality, i.e., thingsin-themselves. ${ }^{26}$ In this respect, Allais concurs with Abela that empirical realism cannot count as anti-realism because it is not a theory of meaning. Empirical and (semantic) anti-realism are very different since Kant's focus is on "possible experience" while Dummett's interest is in "conditions of use and verification". ${ }^{27}$ Although I do not think that for Kant, as Abela as well as Allais claim, there are cognitiontranscendent things or facts, I think both of them are right that transcendental idealism and by implication empirical realism diverge from (semantic) anti-realism. ${ }^{28}$ But my reasons are different from theirs: Empirical is not (semantic) anti-realism because empirical realists hold ontological mind-independence for appearances. Unlike Allais I do not think that appearances are per se mind-dependent and that only things-in-themselves are mind-independent. In cognitive respect, appearances are in fact mind-dependent, i.e., epistemically dependent, but insofar something is given in intuition they are not because the "Stoff" of the inner sense stems from the outer sense and is as such ontologically independent: "This material or real entity, however, this Something that is to be intuited in space, necessarily presupposes perception, and it cannot be invented by any power of imagination or produced independently of perception, which indicates the reality of something in space." ( $C P R$ A 373$)^{29}$ This is why empirical realism is unlike anti-realism not just about propositions but about an ontologically independent world our coherent beliefs must eventually correspond to. ${ }^{30}$

\subsection{The wider scope of Kant's classification}

As we have seen, Kant's classification of empirical and transcendental realism anticipates what in the more recent debate is discussed as the forms of non-metaphysical and metaphysical realism. Both, empirical and non-metaphysical realists embrace

\footnotetext{
${ }^{26}$ Cf. Allais (2003), pp. 370, 388-389. Allais also thinks that there are fundamental differences between Putnam's internal realism and Kant. I think she is right that unlike Putnam Kant rejects the claim that there cannot be only one true theory of the world ("there can be only one true system of philosophy", Metaphysics of Morals, Kant 2004a, AA VI: 207) and that correspondence theory of truth is unacceptable (ibid. pp. 375-376). See also Abela's (1996) denial of similarities between internal and empirical realism, and Gurofsky (2018), pp. 36-48, 183.

27 Cf. Abela (2002), pp. 234-235, 232, 241. For Abela it is clear, though, that Kant holds a "recognition transcendent conception of empirical truth" (ibid. p. 215).

28 Allais (2015), pp. 211-212, thinks, however, that although "Kant's position is importantly different from this kind of anti-realism", i.e., anti-realism that rejects experience-transcendent objects, she also sees "similarities" between anti-realism and transcendental idealism. I agree that with respect to that claim Kant is in fact committed to (semantic) anti-realism.

${ }^{29}$ Cf. Heidemann (1998), pp. 166-174, 220-232; Heidemann (2010), esp. 202-205.

${ }^{30} \mathrm{I}$ can see that what is required here is an inquiry into the possibility of correspondence and coherence coexisting in one theory. But this goes beyond the scope of this paper.
} 
ontological independence, epistemic dependence and veridical coherence, whereas transcendental and metaphysical realists subscribe to ontological independence, epistemic independence and veridical correspondence. This equivalence between the Kantian and the contemporary classification of the forms of realism is remarkable and not just a historical discovery. Moreover, Kant's method of classifying realism has systematic value for present-day philosophy in that it helps to further structure and penetrate the theoretical landscape concerning the forms of realism. By further arrangement of the criteria as invented by Kant and taken up in contemporary philosophy, it is even possible to refine and expand the theoretical options that open up for realism and its forms. Combining the ontological, epistemic and veridical criterion in accordance with the specifications dependence and coherence on the one hand, and independence and correspondence on the other, yields $2^{3}$ options as the table illustrates:

\begin{tabular}{lcccccccc}
\hline & $A$ & $B$ & $C$ & $D$ & $E$ & $F$ & $G$ & $H$ \\
\hline ontological & - & - & + & + & - & - & + & + \\
epistemic & + & - & - & + & - & + & + & - \\
veridical & + & - & + & + & + & - & - & - \\
\hline
\end{tabular}

'+' = dependence, coherence; '-' = independence, correspondence

If we employ the ontological, epistemic and veridical criterion as minimal criteria for pinpointing a form of realism in combination with dependence/coherence and independence/correspondence as minimal specifications, what we receive are eight particular forms of realism. The table should be read as follows:

Option $A$ is the form of realism that holds ontological independence, epistemic dependence and veridical coherence. As I have argued in this paper, this combination matches Kant's empirical and equivalent forms of realism. ${ }^{31}$

Option $B$ holds ontological independence, epistemic independence and veridical correspondence. As shown above, this combination clearly matches Cartesian transcendental realism in the Kantian taxonomy.

Option $C$ does not seem to represent an authentic form of realism since reality is conceived as ontologically dependent, e.g., on God's mind. It is, however, perfectly consistent with it that reality can go beyond what we can know, although it is hard to see how coherence could fit together with cognition-transcendence of reality.

\footnotetext{
31 It should be noted, though, that in the case of empirical realism there is no clear-cut coherence-correspondence distinction. As mentioned above (Sect. 2.1), Kant combines coherence and correspondence such that 'correspondence' represents the nature of truth whereas 'coherence' seems to represent the epistemic criterion for cognizing true judgments: for "[...] the empirical truth of appearances is satisfactorily secured $[\ldots]$ according to empirical laws in one experience [...] for everything is actual that stands in one context with a perception in accordance with the laws of the empirical progression." (CPR A 491-493/B 520-521; I am grateful to a reviewer for this journal for pointing me to this passage). Thus, in the case of (non-metaphysical) empirical realism the veridical dimension must be spelled out in terms of coherence and correspondence. For the forms of metaphysical realism, such as transcendental realism (option $B$ ), the classification works, that is those forms clearly subscribe to veridical correspondence as Kant has already seen.
} 
Option $D$ does not seem to represent an authentic form of realism either because like $C$ it denies ontological independence. But it is thoroughly intelligible to regard reality as ontologically dependent and restrict our epistemic access to it according to what we can know in general in connection with veridical coherence. This option conforms to what I have discussed as (semantic) anti-realism.

Option $E$ is a form of realism because of ontological independence. Given ontological independence it is, like in $B$, of course possible that reality can go beyond what we can know. In view of these two kinds of independence, coherence is, however, problematic for sceptical reasons, since our beliefs about reality could be true, although we would never be able to know this.

Option $F$ is a form of realism for the same reason as is $A, B$ and $E$. However, if reality is ontologically independent it seems at least questionable to hold that reality cannot go beyond what we can know while allowing for the independence of truth. As a form of realism this option would need to make it plausible how our understanding of reality can be theory-dependent whereas truth is independent of what we belief.

Option $G$ cannot count as realism because of ontological dependence. But it is consistent that in this case reality cannot go beyond what we can know and to link epistemic dependence with the view that our beliefs are made true by reality and not by other beliefs.

Option $H$ cannot count as a form of realism either, because of ontological dependence. However, it is possible to believe that reality still is beyond of our epistemic grasp and that therefore our beliefs about the world are made true by the world.

I am not claiming that the table as such is exhaustive and could not be expanded. What is evident, though, is that in order for an option to count as a true form of realism, ontological independence must be accepted regardless of whether epistemic independence is endorsed or rejected (like in $A, B, E$ and $F$ ). However, those options that deny ontological independence do not belong to the spectrum of realism in general but come close to idealism or anti-realism, respectively. As we have seen, this doesn't mean that these options are unintelligible as such, they just do not represent forms of realism. But once the non-realist options have been removed from the table, it is not a big deal to classify non-metaphysical and metaphysical realism. All forms of non-metaphysical realism must at least endorse ontological independence and epistemic dependence $(A, F)$. On the contrary, all forms of metaphysical realism must at least endorse ontological and epistemic independence $(B, E)$. The advantage of classifying option $A$ as a form of non-metaphysical realism instead of anti-realism is that non-metaphysical realists hold ontological independence whereas anti-realists don't. Therefore, according to the applied criteria, $A$-forms of realism are genuine forms of realism.

\section{Concluding remarks: expanding the classification}

Kant's classification of the forms of realism is a remarkable philosophical achievement. Kant succeeds in providing the forms of realism on the basis of a set of criteria that although he doesn't term them ontological, epistemic and veridical can 
clearly be identified in his analysis of types of realism. ${ }^{32}$ These criteria are nowadays still in use in order to structure the theoretical options the forms of realism allow and thereby profile them. The way the contemporary debate construes the problem of realism is a clear proof of the presence of Kant's methodological approach to it. ${ }^{33}$ Of course, existing similarities as such in understanding and analysing realism do not demonstrate that contemporary philosophy refers directly back to Kant. But the fact that in substance the contemporary debate over realism uses the same criteria as Kant cannot be neglected. On the other hand, Kant's impact on the contemporary debate has its limits for the obvious objection to this observation is that the forms of realism Kant considers are not very far-reaching as the number of criteria he applies is too small in order to be able to also grasp the forms of realism the contemporary debate discusses. This worry is well-justified. Kant's account of realism is limited since it only covers the non-metaphysical and metaphysical forms. This is because Kant believed that it would be possible to show the truth of empirical (non-metaphysical) realism by indirect proof, i.e., by showing that empirical and transcendental realism are disjunct and that transcendental (metaphysical) realism is false because it has skeptical and antinomic consequences. What Kant was not aware of is, as the contemporary debate shows, that there are alternative approaches to the realism issue like anti-realism, non-realism, error theories, quietism, etc. that fall outside his classification. ${ }^{34}$ Also, Kant's classification only considers existence, epistemic access and truth but ignores the dimension of property in the sense that some forms of realism might allow for, e.g., classes of properties of objects that are epistemically dependent whereas others are not. As I said above, one cannot expect Kant to anticipate all relevant aspects, realism involves. But it should be possible to extend or modify the list of criteria he applies such that the forms of realism that are yet missing can be integrated. To show, what this would need to look like in detail, is beyond the scope of this paper. My aim rather was to show that the contemporary debate over realism is indebted to Kant's methodology of classifying the forms of realism. ${ }^{35}$

Open Access This article is licensed under a Creative Commons Attribution 4.0 International License, which permits use, sharing, adaptation, distribution and reproduction in any medium or format, as long as you give appropriate credit to the original author(s) and the source, provide a link to the Creative Commons licence, and indicate if changes were made. The images or other third party material in this article are included in the article's Creative Commons licence, unless indicated otherwise in a credit line to the

\footnotetext{
32 In that respect I agree with Abela (2002), p. 6 and Moran (2000), p. 75.

33 Apart from, e.g., Dummett and Putnam, a striking example of this is Miller's (2016) superb entry "Realism" in the Stanford Encyclopedia of Philosophy. What I have coined in this paper Kant's ontological, epistemic and veridical criterion is for Miller the "dimension" of "existence", "independence" and the issue of "truth" that he uses in order to explicate the "many different forms that realism [...] can take".

34 Cf. Miller (2016). Although Kant might respond that these approaches are irrelevant because they do not really address the issue.

35 I have presented earlier versions of this paper in Graz, Göttingen, Berlin, Aarhus, Frankfurt, Dortmund, Utrecht and Bochum. For helpful discussion I thank my departmental colleagues Frank Hofmann, Andy Orlando, Sven Seidenthal and, for debating the table of realisms, Hannes Fraissler. I also thank two anonymous referees for this journal.
} 
material. If material is not included in the article's Creative Commons licence and your intended use is not permitted by statutory regulation or exceeds the permitted use, you will need to obtain permission directly from the copyright holder. To view a copy of this licence, visit http://creativecommons.org/licen ses/by/4.0/.

\section{References}

Abela, P. (1996). Putnam's internal realism and Kant's empirical realism: The case for a divorce. Idealistic studies, 26(1), 45-56.

Abela, P. (2002). Kant's empirical realism. New York: Oxford University Press.

Allais, L. (2003). Kant's transcendental idealism and contemporary anti-realism. International Journal of Philosophical Studies, 11(4), 369-392.

Allais, L. (2015). Manifest reality. Kant's idealism and his realism. Oxford: Oxford University Press.

Allison, H. E. (1976). The non-spatiality of things in themselves for Kant. Journal of the History of Philosophy, 14(3), 313-321.

Allison, H. E. (2004). Kant's transcendental idealism. New Haven and London: Yale University Press.

Bauer, S. (2019). Der Wahrheitsbegriff In Kants Transzendentalphilosophie. Eine Untersuchung zur Kritik der reinen Vernunft, Diss: University of Heidelberg.

Buroker, J. (1981). Space and incongruence: The origin of Kant's idealism. Dordrecht: Reidel.

Buroker, J. (2006). Kant's critique of pure reason. Cambridge: CUP.

Cleve, J. V. (2003). Précis of problems from Kant. Philosophy and Phenomenological Research, 66(1), 190-195.

Dummett, M. (1978). Truth and other enigmas. London: Duckworth.

Gurofsky, S. R. (2018). Making Kant's empirical realism possible. Doctoral Dissertation, University of Chicago. (https://knowledge.uchicago.edu/record/407?ln=en, retrieved: 01-10-2019).

Gurofsky, S. R. (2019). 'Syntheticity and recent metaphysical readings of Kant's Critique of Pure Reason'. In Kant-Studien 110 (appearing).

Heidemann, D. H. (1998). Kant und das problem des metaphysischen Idealismus. Berlin/New York: De Gruyter. (Kantstudien Ergänzungsheft 131).

Heidemann, D. H. (2010). Appearance, thing-in-itself, and the problem of the skeptical hypothesis in Kant. In D. Schulting \& J. Verburgt (Eds.), Kant's idealism. New interpretations of a controversial doctrine (pp. 195-210). Dordrecht: Springer.

Historisches Wörterbuch (1992). Realismus. In J. Ritter and K. Gründer (Eds.) Historisches Wörterbuch der Philosophie. (Vol. 8, pp. 148-178).

Kant, I. (1900). Gesammelte Werke (Ed. by the Royal Prussian (later German) Academy of Science). Berlin: De Gruyter (citation format: AA = Akademie-Ausgabe, volume and page number).

Kant, I. (2000). Critique of pure Reason (P. Guyer \& A. W. Wood Trans.). Cambridge: Cambridge University Press.

Kant, I. (2004a). Metaphysical foundations of natural science (M. Friedman Trans.). Cambridge: Cambridge University Press.

Kant, I. (2004b). Prolegomena to any future metaphysics (G. Hatfield, Trans.). New York: Cambridge University Press.

Langton, R. (1998). Kantian humility. Our ignorance of things in themselves. Oxford: Oxford University Press.

Miller, A. (2016). Realism. In The stanford encyclopedia of philosophy (Winter 2016 Edition), Edward N. Zalta (ed.), https://plato.stanford.edu/archives/win2016/entries/realism/

Moran, D. (2000). Hilary Putnam and Immanuel Kant: Two internal realists'? Synthese, 123(1), 65-104.

Nagel, Th. (1989). The view from Nowhere. New York: OUP.

Okruhlik, K. (1986). Kant on realism and methodology. In R. E. Butts (Ed.), Kant's philosophy of physical science. Dordrecht: Reidel.

Prauss, G. (1974). Kant und das problem der Dinge an sich. Bonn: Bouvier.

Putnam, H. (1980). "How to be an internal realist and a transcendental idealist (at the same time." In R. Haller \& W. Grassl (Eds.) Language, logic and philosophy: Proceeding of the fourth international Wittgenstein symposium (pp. 100-108) Kirchberg/Wechsel, Austria: Springer.

Putnam, H. (1981). Reason, truth and history. Cambridge: University Press. 
Putnam, H. (1982). Why there isn't a ready-made world. Synthese, 51, 141-167.

Putnam, H. (1983). Realism and reason. Philosophical papers (Vol. 3). Cambridge: Cambridge University Press.

Putnam, H. (1987). The many faces of realism. La Salle: Open Court.

Putnam, H. (1988). Representation and reality. Cambridge/London: MIT Press.

Putnam, H. (1990). Realism with a human face. Cambridge/London: Harvard University Press.

Putnam, H. (1999). The threefold cord: Mind, body and world. New York: Columbia University Press.

Stevenson, L., \& Walker, R. (1983a). Empirical realism and transcendental anti-realism. Proceedings of the Aristotelian Society, Supplementary Volumes, 57, 131-177.

Stroud, B. (1984). The significance of philosophical scepticism. Oxford: OUP.

Stevenson, L., \& Walker, R. (1983b). Empirical realism and transcendental anti-realism. Proceedings of the Aristotelian Society, Supplementary Volumes, 57, 155-177.

Van Cleve, J. (1999). Problems from Kant. New York: Oxford University Press.

Walsh, C. M. (1903). Kant's transcendental idealism and empirical realism. Mind, 12(48), 454-472.

Walsh, C. M. (1904). Kant's transcendental idealism and empirical realism (II.). Mind, 13, 54-71.

Westphal, K. R. (2004). Kant's transcendental proof of realism. Cambridge: Cambridge University Press.

\section{Online Encyclopedia}

Adelung, Johann Christoph: Grammatisch-kritisches Wörterbuch der hochdeutschen Mundart (1811) (https://lexika.digitale-sammlungen.de/adelung/online/angebot).

Grimm, Jacob und Wilhelm: Deutsches Wörterbuch. 16 Bde. in 32 Teilbänden. Leipzig 1854-1961 (http://woerterbuchnetz.de/cgi-bin/WBNetz/wbgui_py?sigle=DWB).

Johann-Heinrich Zedlers Universal-Lexicon aller Wissenschafften und Künste 1731-1754 (https://www. zedler-lexikon.de/index.html?c=startseite $\& l=d e)$.

Publisher's Note Springer Nature remains neutral with regard to jurisdictional claims in published maps and institutional affiliations. 